\title{
"Siento, luego pienso" \\ sobre la potencia evocadora de la imagen mental
}

\author{
Pablo Chiuminatto M. ${ }^{1}$
}

\section{Presentación}

Pensemos por un momento qué formas de pudor son las que puede provocar hoy una conversación sobre "erotismo." Es evidente que luego de la amplia presencia mediática que este concepto ostenta podemos sospechar de cierto aire de comunicabilidad que ha adquirido lo erótico como tema. En este escrito nos propusimos abordar algunos aspectos comprometidos en la experiencia erótica, las que implican necesariamente la concurrencia de nuestras facultades sensibles así como aquellas racionales, asumiendo las imágenes mentales como ejemplos privilegiados de superviviencia de una memoria erótica.

Por otra parte, es importante considerar que al momento de discutir sobre erotismo debemos asumir que después del surgimiento del psicoanálisis toda forma de pensamiento, todo texto, así como cada expresión que utilizamos, puede volverse un arma de doble filo, necesaria pero a la vez reveladora de nuestros propios lapsus.

\section{La razón de ser de la imagen}

Merleau-Ponty, en su libro La fenomenología de la percepción, hace una lectura de una frase de Freud, de la Introducción al Psicoanálisis, en la que el médico austriaco establece una máxima con un alcance particular. Freud escribe: "todo acto humano tiene un sentido." Esta deducción implica los más variados aspectos de la constitución de la psicología humana, obligándonos a considerar todo signo o fenómeno bajo un régimen de "razón de ser" (Merleau-Ponty 1975, 175). Todo tendría un sentido y 
este sentido una razón, así como toda razón un sentido. Merleau-Ponty escribe:

Esto, en efecto, equivale a admitir que un síntoma, en el momento en que se establece, siempre encuentra en el sujeto razones de ser, de modo que ningún acontecimiento en una vida está, propiamente hablando, determinado desde afuera. Freud llega a comparar el accidente externo, al cuerpo ajeno que para la ostra es sólo ocasión de segregar una perla (175).

De este modo, siguiendo la propuesta de ambos autores, me pregunto si acaso pensar un cogito sensorial, es decir un "siento luego soy," como instancia primaria de percepción del propio cuerpo, no fundaría las bases de una forma de cogito sexual. Es decir, una conciencia de la formación corpuscular de esa "perla," de la que habla Freud, que albergamos y que precisamente es consecuencia de la acumulación de experiencias, entendidas como la relación misma con lo externo (Nancy 2001).

De modo que cuando comenzamos a aplicar la razón como guía de la experiencia, asistimos (como propone Merleau-Ponty) al "sometimiento de la afectividad penetrada por la inteligencia," lo que permitiría la constitución de aquel sino racional cartesiano de un "pienso luego soy." Esta operación mental indudablemente en esos últimos cuatro siglos, se ha visto cuestionada precisamente por la concreción de los mismos elementos que el psicoanálisis reveló como constitutivos de la sintomatología psíquica (lenguaje, emociones, memoria e imaginación)(Merleau Ponty 1975, 171). De modo que nos enfrentamos a una especie de oxímoron, es decir, la figura imposible y contradictoria formada por la idea misma de pensar lo sexual y por lo tanto lo erótico, desdoblada simultáneamente en la relación -tanto a priori como a posteriori- del pensamiento que lo reprimido manifestaría. Se trataría, lo erótico, de una dimensión en la que la experiencia del deseo se vuelve impensable, porque de alguna manera nos enfrenta a un hecho muy concreto: no se puede pensar la sexualidad y vivirla en un mismo instante, como acto del pensamiento, independiente y voluntario, como si creyéramos que esa perla de la que habla Freud no determinara cada una de nuestras deducciones. Sé que en este momento puede surgir la pregunta sobre la diferencia entre 
erotismo y sexualidad, pero precisamente es la confusión lo que compromete su rol en este texto.

La combinación de una suerte de racionalidad consciente de la raíz sensible de toda experiencia, con el paradigma psicoanalítico de lo sexual, como aquello reprimido y velado, demostraría la imposibilidad de llevar ciertos conceptos que nos interesan -erotismo, sexualidad, y toda la filología amorosa incluida- al campo del pensamiento puro, porque su materialidad oculta precisamente el revés de lo reprimido e inescrutable de la experiencia del propio deseo. Es decir, metafóricamente, pensar lo erótico nos enfrentaría a la observación de un firmamento compuesto por una infinitud de galaxias, constituidas por incalculables grupos de perlas freudianas que se mueven al ritmo enigmático de una fuerza vital que podemos llamar "lo humano."

Merleau-Ponty se pregunta: “¿por qué la sexualidad no es sólo un signo, sino un signo privilegiado?" (176). La actividad erótica es difícil de ser pensada. Podríamos preguntarnos cuál es el sujeto de tal experiencia, para luego comprobar que el pensamiento y la suspensión del juicio, en el goce del cuerpo, no son fáciles de combinar y manipular. Ahora, hay una dimensión que es especialmente importante de discutir. Es una que no necesita ilustración alguna ya que el ejemplo lo pueden traer ustedes mismos a presencia, con su memoria, su experiencia. Se trata de la carga heurística de la imagen, es decir del placer probabilístico implícito en nuestra relación con lo visual, como lugar de despliegue de los mecanismos mnemotécnicos que poseemos y -por qué no decirlo- consecuencia directa de la fantasía y las fantasías. Allí, en esa dimensión compleja, se cruzan tanto el pasado real invocado como actualidad, así como lo virtual constituido como un hecho posible. La experiencia, esa reliquia modelada por el acuñamiento imaginario del que habla Freud, congrega cierta reexaminación interior sensible y sentida, la que, sin embargo, no por eso es menos profunda, racional y al mismo tiempo afectiva y amorosa.

Preguntarnos por lo vivido a través de las imágenes que se despliegan bajo aquel tipo especial de hiato representado por lo que pensamos, implica una serie compleja de procesos conscientes e inconscientes. Lo que sentimos y lo que sentimos cuando pensamos, participa más que de una conciencia que enjuicia, de 
una que, como cuando visitamos un museo, revisita y recorre un complejo panorama de objetos. Se trata de procesos complejos en los que se desenvuelven aquellos "signos privilegiados," como los llama Merleau-Ponty, en total actualidad, porque la remembranza es un presente constante. Signos que evidentemente están parasitados por la cultura visual que nos constituye y determinados por el tipo de "representaciones" mentales que generamos.

Lo erótico está constituido por el intervalo consciente-inconsciente entre sexualidad y racionalidad, de modo que uno de estos aspectos debe sustraerse a la relación necesariamente corporal que implica lo sexual. Esta condición de lo erótico involucra ya no tan sólo la idea de la sublimación del cuerpo en sí mismo por el pensamiento, a través de lo erótico como una forma de racionalidad diferida de la experiencia, del acto, sino más bien del espacio de suspenso que significa la introyección misma como representación mental individual de cualquier experiencia. Un viaje extraño entre la pura evocación y lo transicional, como si pudiéramos divertirnos jugando con esa perla preciosa en una relación a la vez háptica y sinestésica. Se trata entonces de una conciencia estética de lo erótico (evidentemente no libre de aspectos morales constitutivos) manifiesta en el juego virtual visual de su poder mental.

¿Cómo podemos pensar aquella actualidad manifiesta en el acto de sentirnos pensar y pensarnos sintiendo? Tal vez es lo que más se asemeja a una forma de pensamiento con el cuerpo, no sólo con la mente sino del cuerpo. En este caso puntual sería interesante considerar ya no la relación con los objetos fuera de uno mismo, en términos del erotismo relacionado con la producción de imágenes por ejemplo, sino quedarnos un momento en la experiencia interior imaginativa, es decir, en la metáfora de la interioridad erótico-sexual que cada uno posee. La esfera de la imaginación es la dimensión preponderante de la evocación, entendida como ámbito predominante de la representación mental, con esa carga "real" innegable, radicada precisamente en lo virtual de la experiencia. Es una forma de lo real que poco tiene que ver con la verdad, sino más bien con la ficción, con la potencia verosímil de la luminosidad que proyectan las imágenes internas, aunque éstas no sean completamente claras y distintas 
(parafraseando a Descartes); pero que parecieran estar, como las perlas, iluminadas desde dentro. Recordándonos así algunas magnitudes que vienen a nuestra mente y que tienen un efecto sensorial, como si estuviéramos tocando, gustando, oyendo, viendo y oliendo, en plena actualidad. Están presentes, están vivas, las imágenes eróticas, esas perlas, son parte de un mundo marino sumergido pero resplandeciente.

La liberación que significa la imagen, en la fantasía erótica, como alteridad transformada con la que nos relacionamos como ante un otro virtual, por medio de nuestro pensamiento (como diría Nancy siguiendo a Lacan) plantea la imposibilidad de la relación, ya que siempre estaríamos en esa dimensión perceptiva del cuerpo ajeno mediado por el propio cuerpo (Nancy 2001, 9). Sin embargo, a partir de esto, podríamos preguntarnos por ese momento en el que aparece la sensación y simultáneamente la conciencia perceptiva, en correspondencia con la constitución del imaginario sexual, todo ello por medio de imágenes. Así podremos preguntarnos si es la razón, plenamente consciente, valorativa, lo que transformaría lo sexual (supuestamente automático, mecánico e infantil) en erotismo (maduro y racional); o sea, en conciencia sexual, en cogito sexual, tratándose acaso de una instancia aún no pensada ni pensable en los límites de nuestra actual conciencia (un cuerpo racional). Merleau-Ponty describe una escena precisa:

Adivinamos aquí un modo de percepción distinto de la percepción objetiva, un género de significación distinto de la significación intelectual, una intencionalidad que no es la "pura conciencia de algo." La percepción erótica no es una cogitatio que apunta a un cogitatum; a través de un cuerpo que apunta a otro cuerpo, se hace dentro del mundo, no de una conciencia. Un espectáculo tiene para mí una significación sexual, no cuando me represento, siquiera confusamente, su relación posible con los órganos sexuales o con los estados de placer, sino cuando existe para mi cuerpo, para esta potencia siempre pronta a trabar los estímulos dados en una situación erótica y a ajustar una conducta sexual a la misma. Se da una "comprensión" erótica que no es del orden del entendimiento, porque el entendimiento comprende advirtiendo una experiencia bajo una idea, mientras que el deseo comprende ciegamente vinculando un cuerpo al cuerpo (Merleau-Ponty 1975, 173). 
El pensador francés propone una distinción, eso que permite "distinguirme," y que "me" tiene separado del mundo. Esta condición es, al mismo tiempo, lo que posibilita que en algún momento establezcamos una relación con eso que está fuera de nosotros mismos, en este caso una relación racional-sensible, que sería adonde remitimos lo sexual antes de lograr concebir la utopía racional de un cuerpo separado de la mente. Pero, ¿en qué instante ideamos eso que llamamos "nuestra sexualidad," como dimensión de autonomía individual? Cuando somos capaces de evocar concientemente imágenes y sensaciones o cuando llegamos a proyectarlas hacia otro $u$ otros, en los que reflejamos una libertad asociativa de "imágenes."

En general, pareciera ser que eso que podemos vivenciar de lo erótico no es sino el propio erotismo, siempre actual para mi cuerpo y proyectable en el mundo, del modo como lo propone Merleau-Ponty:

El ser humano no muestra ordinariamente su cuerpo y, cuando lo hace, es ora con temor, ora con la intención de fascinar. Le parece que la mirada ajena que recorre su cuerpo lo hurta a sí mismo, o que al contrario, la exposición de su cuerpo le entregará el otro sin defensa, y que luego será el otro el reducido a la esclavitud. El pudor y el impudor se dan, pues, en una dialéctica del yo y del otro, que es la del dueño y el esclavo: en cuanto tengo un cuerpo, puedo ser reducido a objeto bajo la mirada del otro y no contar para él como persona, o bien, al contrario, puedo pasar a ser su dueño y mirarlo a mi vez, pero este dominio es un callejón sin salida, porque, en el momento en que mi valor es reconocido por el deseo del otro, el otro no es ya la persona por la que yo deseaba ser reconocido, es un ser fascinado, sin libertad, y que por eso, no cuenta ya para mí. Decir que tengo un cuerpo es, pues, una manera de decir que puede vérseme como un objeto y que quiero que se me vea como sujeto, que el otro puede ser mi dueño o mi esclavo, de modo que el pudor y el impudor expresan la dialéctica de la pluralidad de las conciencias y poseen una significación metafísica (173).

Seguramente recordarán la propuesta freudiana del Edipo y su modelo de superación de estadios sexuales. Establecer una imagen separada de nuestra madre, de nuestro padre, constituir nuestra propia sexualidad, son todas categorizaciones que 
en términos psicológicos son representadas a través de imágenes: imagen paterna, imagen materna, auto-imagen. Al mismo tiempo, en el caso de Freud, éstas figuras surgen de un panteón particular como es el de la mitología occidental, imágenes paradigmáticas, modelos, como se dice en una clase de dibujo.

¿Cuándo surge la conciencia sexual, hay acaso una conciencia erótica? ¿Cuándo nos la representamos mentalmente? ¿Cuándo nuestro cuerpo percibe algo otro aunque no posea las herramientas enunciativas para transformar aquello en una especie de conciencia del propio cuerpo, o es esa precisamente la conciencia del cuerpo que el inconsciente trabaja en términos de represión, con consecuencias figurativo-mentales que bastarían para demostrar su potencia? No estoy pensando en significaciones sexuales o psicoanalíticas solamente, sino en la posibilidad misma de recuperar, a través de la memoria, ciertos fragmentos perceptivos, imágenes, rasgos que podemos recobrar de modo virtual y que permiten establecer la relación en sí de lo erótico, más poderoso que lo puramente mental y que podemos asumir dentro de un margen cognitivo, compuesto equitativamente por sensibilidad y razón, por cuerpo y mente. Porque en el mundo erotizado, como plantea Merleau-Ponty: "A cada instante las cosas ocurren como si el sujeto ignorara lo que hay que hacer" (172).

Entonces podríamos establecer una relación más y preguntar: ¿desde qué momento somos conscientes de aquello que solemos llamar "deseo," el mismo que estaría mediado por un cogito de la sensibilidad y secundado por su reconocimiento como índice o signo interno, es decir por una imagen que permite saber que sabemos de nuestro deseo? Así, volvemos al problema que se plantea en el momento sexual, considerado como actividad sexual. No puedo estar pensando la relación con el otro, positiva y materialmente, porque -en palabras de Merleau-Ponty- estamos comprometidos en el nudo que representa el cuerpo en nuestra relación con el mundo: "Ser cuerpo es estar anudado a un cierto mundo, vivimos nosotros, y nuestro cuerpo no está, ante todo, en el espacio: es del espacio" (165). Reiteración que complejiza aún más el hecho de teorizar sobre este tipo de experiencias, pues la objetividad quedaría urdida por las propias aprensiones de lo que nos constituye históricamente 
como sujetos (básicamente simbólicos, sintomáticos y reprimidos). Estas experiencias complejas son algo así como "el deseo" representado en elementos materiales o de ficción -perlas, si quisiéramos- apreciables en las conformaciones simbólicas del arte en general, pero también en la disposición de los objetos en nuestra casa y en el modo en cómo nos acicalamos antes de salir a una cita.

A partir de Nancy -siguiendo su reflexión- podemos pensar la diferencia de sexo y si eso reproduce diferencias de imaginarios que nos permitieran pensar ya no tan sólo la distinción física, sino también la diversidad simbólica implicada en el acervo imaginario que la idea de una determinada personalidad representa. ¿Cuáles son los signos que traemos a nuestra mente a partir de nuestra diferencia sexual? Nancy va a decir que la diferencia no es de individuos, ni de naturalezas, ni de grados, sino que se trataría de una diferencia del sexo en tanto que difiere de sí, que permite la distinción entre "yo y todo lo que no sea yo." El sexo es, por lo tanto: "Vivir sexualmente, desde todo punto de vista, el ser diferente de sí. Diferente en tanto que diferenciación según las gradientes múltiples y los devenires entre lo masculino y lo femenino, lo homo y lo hétero, lo activo y pasivo" (Nancy 2001, 30).

Lo anterior, evidentemente nos obliga a preguntarnos por la propia calidad de la relación con los elementos que se enuncian, es decir, que hacen posible la analogía visual con lo sexual, como rendimiento imaginativo corporal y mental, junto a un pensamiento del goce como algo productivo, voluntario y consciente. Por lo tanto, interrogarnos por la conciencia en el momento en que vivimos la sexualidad, correspondería a preguntarse por el espacio en que residiría el pensamiento cuando hay pura complacencia de los sentidos, como ocupación del cuerpo. Se trata de una dimensión ontológica que alberga tanto a la razón como a la sensibilidad, como un modo original de la conciencia, rompiendo con la utopía de algo así como un pensamiento puro (MerleauPonty, 171). Si quisiéramos continuar con las divisiones y las categorías, una pregunta posible sería: ¿Cuál será la representación que tenemos de esa especie de hiato o vacío que no podemos presenciar y al que, al mismo tiempo, asistimos cuando vemos con los ojos de la mente esos objetos del deseo del cuerpo? 


\section{Una imagen es siempre virtual}

Tal como propusimos en la sección anterior, este texto plantea ya no la contemplación del objeto pensado fuera, expresando una estética de lo erótico autónoma y pura, sino basada en la constitución del propio cuerpo en la percepción, como reconocimiento integral de la experiencia sensible del pensamiento. Si esta operación la asociamos directamente con la formación de imágenes, como si se tratara de objetos transformables por el arte, podemos describir de mejor manera el juego hegemónico de los modelos perceptivos y de la sensibilidad misma. David Freedberg en su libro el Poder de las imágenes escribe:

Contemplar hasta la saciedad es precisamente el tipo de mirada que fetichiza el objeto, que le otorga cualidades vitales y hace que reaccionemos ante él como si estuviera vivo. Se convierte en un objeto de interés sexual, como demuestran claramente los síntomas de la mirada en cuanto mirarlo -el objeto se convierte en mirarla- la persona (Freedberg 1989, 390).

¿Qué tipo de vitalidad es la que representan las imágenes mentales y la atracción transicional que operaría sobre ciertos objetos? No necesariamente se trataría de cosas que están fuera, sino más bien de objetos de la imaginación, representaciones que cada uno es capaz de hacerse de aquello que tiene la potencia de revitalizar y, en un cierto sentido, excitar.

Luego, obligatoriamente habría que preguntarse por la relación que existe entre la visualidad general, y aquélla que, en términos de las artes visuales, nos ofrecen actualmente los medios, la tecnología y la "erotización" misma de lo mediático, como teatro de lo reprimido. Preguntarnos si habría en lo tecnológico una posibilidad de mayor mediación o una mediación distinta para la visualidad, considerando el cambio epistemológico que se plantearía al interior de la relación misma con las tecnologías de la información. Es decir, cuestionar si no es acaso la misma tecnología que media la imagen la que cumpliría con las ansias escópicas (visuales) que, desde mucho antes, la sexualidad en particular y la imaginación en general proponen como virtualidad mental, en tanto que consiste en la producción de imágenes erotizadas. 
Antes que el teléfono, la fotografía vino a crear una instancia de identificación privilegiada del movimiento, pero también perfeccionó un avance fundamental en la representación de los cuerpos y en el incremento de la calidad gráfica de lo pornográfico. Esto invita a preguntarnos por el nacimiento de la pornografía en términos de salto cuantitativo, de esa especie de efecto de realidad que tiene la imagen fotográfica y, por lo tanto, la capacidad de establecer un vínculo sensorial más directo, a modo de precisión visual, porque efectivamente la fotografía es más real. Si bien no estamos confundiendo la imagen con algo así como lo real, reconocemos el principio realista que en el caso de la imaginación funciona persistentemente en la imagen, fundamentalmente en las imágenes mentales, que son siempre reales. A ese real me refería al inicio de este texto cuando planteaba la fuerza virtual de lo imaginario, vinculado con los sentidos y su tránsito sexual, cristalizado en la perla de Freud. El real de la imaginación es un real en términos de virtualidad imaginable, porque es convocado en la misma materialidad, que es la materialidad del deseo y la imaginación.

A partir de este modelo de estratos pulidos por el tiempo podemos pensar la valoración de ciertas zonas del cuerpo por sobre otras, áreas de manifestación de una escena privilegiada de desplazamiento visual. Esta estimación ha ido variando en la historia de la representación y de la carga sexual o moral que se le atribuye a la imagen del cuerpo. Hoy, una rodilla no es nada a diferencia de lo que sí podrían ser aún otras zonas. Hace cien años mostrar el pie bastaba para el repudio. Habría que cuestionar el hecho que esta especie de valorización de la presentación de fragmentos de cuerpos desnudos o del desnudo en sí mismo fragmentado, en los medios de comunicación, aparece sospechosamente como una relación libertaria: se habla de "destape." En general, obviamente, la libertad ganada en el siglo XX consiste en desnudar preferentemente el cuerpo femenino. Podemos recordar la frase (ya histórica) que aparece en uno de los afiches del grupo de artistas feministas Guerrilla Girls, del año 1989, que señalaba: “ ¿Tienen que estar desnudas las mujeres para poder estar en el Museo Metropolitano de Nueva York? -y más abajo- El 5\% de los artistas en la sección de Arte Moderno son mujeres, pero el $85 \%$ de los desnudos son femeninos."

Se ha ganado el espacio de la presentación del cuerpo y de 
la fetichización, como diría Freedberg, donde de alguna manera la fotografía y su correlación con la producción de la televisión y el cine, tiene un sistema de representación asociado, el que manifiesta esta trama del cuerpo por niveles, así como revela el despropósito de ciertos grados de censura (Freedberg 1989, 398). Pensemos por un momento en la Venus de Milo, que permanece aún desnuda en un pasillo lateral del Louvre y, al mismo tiempo, en los millones de dólares que tuvo que pagar una cadena de televisión norteamericana, por una alocada superestrella de rock que dejó ver parte del busto, mucho menos de lo que muestra la Venus, por cierto. Sin duda, las imágenes más pornográficas no están en el desnudo porno, recordando la respuesta de Larry Flynt al juez, quien en el juicio por publicar la revista Hustler en los setenta, presentó una serie de imágenes del desastre humanitario provocado por la guerra de Vietnam.

No trataremos aquí el problema de la censura en sí, que me parece tiene una profunda relación con el trabajo de separación de cuerpo y mente que algunas tradiciones de pensamiento han promocionado, como pieza clave para describir los límites de lo reprimido. Freedberg anota algo interesante:

Si examinamos los grabados censurados del siglo XVI, vemos que una pequeñísima proporción mostraban desnudos femeninos. Globalmente, el interés por el cuerpo de la mujer parecía ser menor que el despertado por la ilustración e insinuación del acto sexual propiamente dicho. Existen ciertamente muchos más penes en erección en los grabados del siglo XVI que en las fotografías del siglo XIX. Diferencias de esta índole tienen a la vez un carácter cultural y circunstancial, pero si queremos defender esta postura o (en mi opinión sería irrelevante) argumentar que se trata de dos géneros distintos y que las fotografías no son narraciones o son menos narrativas que los grabados del siglo XVI. Estas diferencias nos obligan a considerar aspectos a los que hasta el momento no hemos prestado la debida atención (399).

Este índice de diferencia que el autor reconoce en la fotografía y que, de paso, da cuenta de una proporcionalidad inversa entre realismo y pornografía, permite preguntarnos dónde está la potencia sexual de la imagen ¿En la mirada o en el ir y venir? ¿Dónde reside lo sexual, está en la foto o en mis ojos? Si el poder 
de la imagen residiera solamente en la desnudez, bastaría con la vestimenta, pero no es así. La fantasía desiderativa está ligada a una acción o conclusión definitiva del hecho mismo, demasiado real para el imaginario, atravesando desde lo pornográfico a lo anatómico. Si lo pensamos como una metáfora actual del zapping, esto nos lleva desde los reportajes del National Geographic, donde aparece el cuerpo antropológico, al Discovery Health, donde el cuerpo es tratado anatómicamente y de ahí al canal Playboy donde el cuerpo simbólico ocupa toda la pantalla.

En los distintos patrones de valoración de la imagen que han existido durante los últimos siglos, se aprecia la confusión entre inculpar a la imagen misma, como objeto que ocupa preferentemente la representación sexual, como una llamada iconoclasta; o incriminar al proceso cognitivo mismo que nos permite traer las imágenes a la mente, es decir, la memoria pensada como una forma de iconofilia o de amor por las imágenes.

Finalmente, la pregunta que se impone es aquélla que interroga por una relación de la especie (humana) con el poder de la representación en sí (de lo humano), lo que supera ampliamente cualquier lineamiento estilístico o cualquier tipo de gramática de la imagen y de pensar una "estética de lo erótico" fundada en las determinantes visuales que duermen en el conocimiento de lo humano. Tal vez, a partir de esto, podríamos repensar las categorías del desarrollo sexual que plantea el psicoanálisis freudiano en una cadena de superaciones (Edipo, Narciso, Antígona, etc.), las que sin duda se reducen a imágenes o a las consecuencias de la imagen "propia y ajena," es decir, del mundo como todo lo que no sea uno-mismo (narcisismo, paranoia, sadismo, histeria, etc.). La superación psicoanalítica como constitución de un pensamiento adaptativo social, consistiría tal vez en abandonar un estado de la "imagen" para pasar al siguiente, como relación equilibrada con lo propio y lo ajeno. Todo aquél que no pueda transitar sanamente por estos caminos sufre algún tipo de trastorno, perturbación de su imagen y de la imagen que se hace del mundo. Es decir, inminencia del estallido de sentido que Freud identificó con el criterio de la "razón de ser" de las cosas. ¿Qué tipo de sentido sería ése? Un sentido no en términos sólo cognitivos sino, más bien, sensorial y afectivo, el que transforma efectivamente nuestra valoración de "lo real." 
¿En qué lugar estaría eso que logra traducir la imagen sensorial de lo físico y de esta relación en sí misma interior, manifiesta en el hecho que las imágenes puedan evocar, transferir, traducir, trasladar, nuestros propios deseos sexuales? Freedberg escribe:

En todo momento he prestado atención a la condición apofántica y analítica de la represión y el fetichismo, y de forma gradual a la tensión que surge del sentimiento de que existe una frontera -sentimiento que no equivale necesariamente al conocimiento. Ya he descrito algunos modos en que un amor positivo por una imagen puede convertirse en un amor negativo o en un amor de las personas menos adecuadas: es lo que se denomina normalmente idolatría (416).

Eso que Freedberg reconoce como adoración de una imagen, llevado al comportamiento general, puede ser entendido como perversión, es decir, fijación. Sin embargo, paradógicamente, cuando esa misma energía es remitida al pensamiento, al proceso mismo de la especulación, decimos que es reconcentración, profundidad, progreso y superación de lo humano. Una persona con fijaciones básicamente visuales es un pervertido, maravillado por el brillo de la perla. Mientras uno que posee fijaciones conceptuales, es un filósofo, un pensador puro. Evidentemente, este desequilibrio da cuenta de cierta diferencia insalvable para quienes trabajan con imágenes, es decir, con un material equívoco e inestable en su significación, versus un pensamiento puro y libre de los vestigios sensibles que fundan las imágenes.

$-¿$ Curioso, no?

\section{Nota}

1 Pablo Chiuminatto, Doctor en Filosofía con mención en Estética y Teoría del Arte y Magíster en Artes Visuales, Universidad de Chile. Este texto forma parte de la investigación FONDECYT N${ }^{\circ} 1040530$ y corresponde a la edición del material de dos clases dictadas en el del Centro de Estudios de Género y Cultura en América Latina de la Facultad de Filosofía y Humanidades, Universidad de Chile, gracias a la invitación de la profesora Olga Grau, diciembre de 2004. 


\section{Bibliografía}

Freedberg, David. El poder de las imágenes. Madrid: Cátedra, 1989.

Merleuau-Ponty, Maurice. Fenomenología de la percepción. Barcelona: Península, 1975.

Nancy, Jean-Luc. $L^{\prime}$ «il y a» du rapport sexuel. Paris: Galilée, 2001. 